\title{
Problems of water lifting machine systems control in the republic of Uzbekistan with new innovation technology
}

\author{
Rustam Ergashev ${ }^{*}$, Fotima Artikbekova, Gulnora Jumabayeva and Farouddin Uljayev \\ Tashkent Institute of Irrigation and Agricultural Mechanization Engineers, Waterpower exploitation \\ and pumping stations, 100000, Tashkent, Kara-Niyaziy str.
}

\begin{abstract}
The article presents the results of the study of the main categories of losses for the elements of irrigation systems, shows the experience of using pumping equipment on irrigation systems, discussed methods for increasing the volumetric efficiency, improving the hydraulic conditions for supplying flow to the impeller and reducing cavitation. The purpose of the research is the scientific substantiation of the usage of samples of modern pumps, in modern water-lifting systems in the context of import substitution programs with innovation technology. The results of the study of the main categories by irrigation system elements are presented, the experience of pumping equipment use on irrigation systems is described, the methods for increasing the volumetric efficiency, for improving the hydraulic conditions for supplying the flow to the impeller and reducing the cavitation wear are examined in the article. The complex solution of such problems as the increasing the efficiency of the pumping equipment was proposed, which allowed to increase the actual performance factor of the given pump from 83 to $88 \%$, compared to the factory data.
\end{abstract}

\section{Introduction}

The Republic of Uzbekistan, being one of the most saturated regions of the Asia about using pumping equipment in amelioration, in the conditions of a growing deficit of material, technical and energy resources in the coming years may find itself in an extremely difficult situation for water supply for irrigation and diversion of saline water.

In the last 20 years, due to the depletion of the equipment life of most pumping stations (PS) shorted to $50 \ldots 55 \%$, the problem of improving reliability becomes extremely urgent. Due to cavitation and abrasion by weighted sediments the wear of the elements of the flow paths of pump equipment (PE) during operation leads to a deterioration of operating conditions $[1,2]$.

\footnotetext{
* Corresponding author: boxa_833@mail.ru
} 


\section{Methods}

To assess the reliability of analyzed possible failures. In the condition of absence of relevant data, the analysis was done with using information on the failures of similar objects; with build failure models for the assessment of the occurrence of specific failures, with establishing quantitative indicators of the reliability of the elements, comparing the obtained indicators of reliability of objects with the reliability indicators required by technical conditions [7-10]:

$$
P_{\text {calc }} \geq P_{\text {req }}
$$
operation;

there: $\mathrm{P}_{\text {calc }}$ - calculated value of the lower bound for the probability of failure-free

$\mathrm{P}_{\text {req }}$ - required probability of failure-free operation.

When condition (1) is not satisfied, requirement for reliability is considered as not fulfilled and it is necessary to provide a revision that will ensure the fulfillment of the relationship.

When evaluating parametric reliability, the reliability condition is written as follows:

$$
A \geq B
$$

there A - potential ability of a design to resist to external influences;

B - external action.

Inequality (2) can express the condition of reliability of an object for any limiting condition (stability, load capacity, deformability, etc.).

\section{Results and discussion}

In the list of causes of failures, which reduce the reliability of the operation of the PE, deformation of the water supply facilities (intake chambers, suction pipes and discharge, siltation of the supply channel, vestibules, gate place) is of special importance, and air is sucked into the flowing part of the equipment. With water intakes from open sources, the use of new water intake chambers gives significant savings in investment and time and greatly facilitates and reduces the cost of operation [3]. [11-16].

As an example, we estimate the reliability of PS, the scheme of which is represented as a consecutive connection of ten elements (table 1).

Table 1. Values of the reliability of the PS elements

\begin{tabular}{|l|c|l|l|}
\hline Element & $P_{\mathrm{Hi}}$ & Element & $P_{\mathrm{Hi}}$ \\
\hline Inlet channel & 0,90 & $\begin{array}{l}\text { Main } \\
\text { aggregates }\end{array}$ & 0,90 \\
\hline $\begin{array}{l}\text { Chamber } \\
\text { channel }\end{array}$ & 0,85 & $\begin{array}{l}\text { Pressurized } \\
\text { water } \\
\text { conduit }\end{array}$ & 0,94 \\
\hline Pumping pipe & 0,86 & $\begin{array}{l}\text { Siphon water } \\
\text { outlet }\end{array}$ & 0,85 \\
\hline $\begin{array}{l}\text { Containment } \\
\text { structure (CS) }\end{array}$ & 0,81 & $\begin{array}{l}\text { Backbone } \\
\text { channel }\end{array}$ & 0,92 \\
\hline Water receiver & 0,89 & $\begin{array}{l}\text { Electrical } \\
\text { substation }\end{array}$ & 0,99 \\
\hline
\end{tabular}


Modern detection of failures (gradual and sudden) helps to prevent a decrease in the efficiency of NA operation and especially possible emergency situations leading to the termination of water supply.

The operation of the PS in irrigation systems requires the improvement of the design of their individual elements, taking into account the requirements for the stability of operation in the regional conditions of the Republic of Uzbekistan (high content of abrasive particles and fin in pumped water, severe climatic conditions). On systems of machine water lifting (MWL) practically all kinds of the pumping-power equipment are maintained.

Long-term exploitation of destroyed equipment in conditions of tougher regimes of its operation leads to the following negative consequences:

1. More than half of accidents and failures are caused by physical wear of the equipment (impeller, impeller chamber, bearings), i.e. the main nodes, the restoration of which requires complete disassembly with decommissioning for a long period.

2. The average weighted efficiency of equipment decreases, and environmental characteristics deteriorate.

The exploitation conditions of pumping equipment in Central Asia are very difficult. They are determined by a high content of solid suspended particles in the pumped water - 6 ... $15 \mathrm{~g} / \mathrm{l}$, high ambient temperature of $35 \ldots 50^{\circ} \mathrm{C}$, a year-round cycle of exploitation (during the winter period, reservoirs are filled, flushing irrigation, etc.) high mineralization of water - up to $25 \mathrm{mg} / \mathrm{l}$. The result of these factors is a relatively low life of the pumps 2000-4000 hours before overhaul and their efficiency. Hence a whole series of specific scientific, technical, and technological tasks to improve the reliability of management of the National Assembly.

The scale of renewal of investment policy requires both new thinking and stricter requirements for resource-intensive projects. Reconstruction of the MWL can give the greatest economic and environmental effect [1].

In the system of the Ministry of Water Resources of the Republic at the present time more than 5 thousand PE are operated. By reducing the specific energy consumption, monitoring and increasing the average operating efficiency of the elements of the National Assembly, it is possible to significantly reduce operational costs and increase the reliability of operation of the National Assembly.

Unlike a number of other machines, there are no normative and technical documentation for pumps, in which the nomenclature of structural parameters of the technical state-the characteristics directly determining the operability of the unit and changing under the influence of various technological and operational factors-would be clearly stipulated. In literary sources, however, many different pump characteristics are proposed as these parameters, often without sufficient justification and experimental confirmation.

In the technical literature there is practically no data on the effect of certain PE units and elements of the hydraulic complex of the National Assembly on performance characteristics. The lack of priority research on this problem makes it impossible to optimize the PE regimes at the current level of operation and use of diagnostic systems. According to the SRIIWP technical resource of the pumps, as a rule, does not exceed 3,5 thousand hours, and the operational efficiency is lower than the calculated values by $5 \ldots$ $7 \%$. It is necessary to take into account the fact that the first NA of the Amukarakul canal has been in operation since $1961 \ldots 65$ years, and the lifespan of other PSs exceeds $25 \ldots 30$ years. The aging of equipment and structures will inevitably lead to the need to consider the issues of operation and reconstruction of systems from the standpoint of reliability theory and water-saving technologies. The existing negative experience of a sharp increase in cavitation-abrasive wear, vibration and emergency shutdowns of aggregates, accompanied by periodic disturbances of the flow, can not yet be comprehensively evaluated. Under these conditions, the sustainability of the exploitation of $\mathrm{PE}$ is of particular importance. It is 
necessary to determine mathematically and economically the expediency of operating the PE while reducing its operating parameters (primarily efficiency) below the calculated ones. The stability of the work determines the characteristics of water and energy saving technologies of operation of the National Assembly.

The main methods for determining the wear of PE parts are known in terms of changing its technical parameters; evaluation of wear and tear on the change of technical parameters, micrometry, weighting method, chemical analysis, profilography, method of holes and prints, method of radioactive indicators, activation analysis, etc.

Due to the wear of the bearing guides, the technical parameters of the PE change, the vibration and water flow rate for lubrication increases.

Vibration tests can be carried out with a view to:

a) determining that the vibration does not exceed the norm determined by the state of the pump;

b) identify and eliminate the design flaws of pumps, leading to increased vibroactivity;

c) control the quality and manufacture of the pump (balance, gaps in the supports);

d) determine the scope of applicability of the pump in terms of parameters (feed, cavitation spare);

e) identify the processes occurring in the pump.

The method of work is to increase the stability and efficiency of operation of all elements of the hydraulic unit of the National Assembly, save energy and other resources on the basis of assessing the technical condition of the buildings and pump and power equipment of the National Assembly.

The most rational and progressive methodology is the planned system of technical operation of pumping stations, which represents a set of organizational and technical measures that ensure optimal operating conditions for the National Assembly. A drastic reduction in the costs of the operation of the MWL can be achieved through the new energy and resource-saving technologies of the PE conjugation structures.

During the period of independence of the Republic, scientific and operational organizations managed to solve a number of issues of increasing the reliability and stability of the PE. However, at large MWL, which are the main consumers of material and technical and energy resources, the problem of their reduction can not be solved without the introduction of new technologies for the operation of MWL and PS, taking into account specific differentiated energy and resource costs in all conjugating structures of the National Assembly.

In addition to saving energy resources, managing the modes of the associated facilities of the National Assembly provides significant savings in water resources associated with the elimination of water losses at the borders of the limiting elements.

The authors propose to use the original (on the level of inventions) designs of mating structures and installations for the entire length of the hydraulic unit of the National Assembly for the realization of these goals and resource saving tasks. After the analysis of full-scale tests, combined structures with complex functions (simultaneous protection from silting and entering by the fin, control of flow distribution) and fundamentally new technologies for their operation will be created.

The development of a methodology for determining the demand for electricity for water-lift for the MWL, its mathematical expression and the implementation of an energyefficient management model for the operation modes of the interfacing structures and water distribution on one of the real systems will allow to obtain no less than 6-7 million $\mathrm{kWh}$ of economy at each major cascade of the National Assembly. With the further development of market relations in the process of water use in agriculture, the estimated energy costs can become the basis for future tariffs for irrigation water. 
The most complex and dynamic in the management of water supply regimes are systems with a cascade scheme of large irrigation systems. Such systems allow certain purposeful regulation of the water supply regime, the prevailing criterion of which until recently was the maximum satisfaction of water users' applications.

The urgency and novelty of the studies are determined by their orientation to mobilizing reserves of resource and energy conservation that have not been applied due to the limited capabilities of traditional principles, the management of technological regimes of the MWL.

It is necessary to determine the feasibility of operating the PS with a decrease in operating parameters (primarily efficiency) below the calculated ones.

Main measures for resource saving and reduction of the cost of water supplied to the WML:

- information and advisory systems for managing the modes of the conjugating structures of the National Assembly based on the main criterion of their efficiency. Refined calculation of the efficiency of the main elements of the hydraulic unit of the National Assembly in various regional conditions;

- elimination of water re-supply in the absence of regulation of the supply to the PS of the head of the MWL and maximum use of the potential energy of surface water sources; liquidation of unproductive losses of electric power, pressure and water level drops, siltation of the evacuation chamber, reduction of the water lifting height due to exclusion of water supply above the level in the siphon water outlets of the PS; - introduction of energysaving technologies of operation of the National Assembly, combined devices for changing the flow structure. Adaptation of the method of differentiated costs to the management of modes of PS stages.

The primary problem of the operation and reconstruction of the MWL is currently divided into 2 parts:

1. Development of new energy- and resource-saving operation technologies with a possible MWL ring and transfer of their water intakes.

2. Investigation of the impact of irrigation on the operating regime and economic efficiency of prospective hydropower stations, and the development of small hydropower.

A sufficiently formalized and operative method of evaluation is needed, which allows to combine in a single indicator the influence of a large number of qualitative and quantitative factors of different significance.

A similar problem was considered by the International Commission on Large Dams (ICLD) in relation to the assessment of the need to automate the field observation system. According to the recommendations of ICLD, the state of the PS is characterized by eleven quantitative and qualitative factors [3].

Because of the incomplete solution of the problem of controlling the solid flow of rivers, most of the material and financial resources directed to operational activities are spent on cleaning the systems from silting, repairing the equipment from abrasive wear.

New technologies make it possible to solve a number of interrelated tasks of increasing the efficiency of operation with increasing efficiency of pumps, water saving with increasing volumetric component of efficiency and safety of operation of large hydraulic structures. These include the National Assembly with unique pumps installed in the PS cascades in Kashkadarya, Bukhara, Surkhandarya and other regions of the Republic [4].

With the implementation of investments, the equipment of one of the unique modern stations (totally in the Republic of 24 PS) will be 170-190 thousand USD, the pioneer project of the standard PS - 11-12 thousand USD. 


\section{Conclusions}

1. The samples of modern pumps in the context of import substitution programs have been developed at SRIIWP and TIIAME. Practical results of the study and the main design dependencies of new pump designs to reduce pump wear are used by design organizations, operation departments of the National Assembly and manufacturing plants. Studies on this subject have been tested in JSC "SUVMASH", at the National Assembly of Tashkent, Bukhara, Surkhandarya Province. The expected annual economic effect from the introduction of the results of works is about 1718 million s. for the introduced pumps. A licensing agreement is envisaged for the use of a number of samples in foreign projects.

2. The abrasion and cavitation have a particular impact on the wear of irrigation pumps. The process of cavitation is accompanied by the appearance of significant local mechanical forces, chemical, electrical and other phenomena. Reduction of cavitation wear is solved by the authors due to the improvement of the hydraulic conditions of water supply.

3. At present, work continues on the integrated solution of problems of increasing the volumetric efficiency. A comparative analysis of the test results showed that the actual efficiency of the new pump is increased from 83 to $88 \%$ compared to the factory data.

\section{References}

1. Report of the Deputy Minister of Agriculture and Water Management of the Republic of Uzbekistan Sh.R. Khamrayev at the regional conference devoted to preparations for the 6th World Water Forum: "Uzbekistan's water industry on the way to overcoming destabilizing factors based on the introduction of innovations and international water law" (Tashkent, May 12-13, 2011);

2. National Report of the Republic of Uzbekistan. As part of the UNEP program to promote and assist developing countries in the implementation of the Johannesburg Plan for the implementation of the goal "Action Plans for Integrated Water Resources Management and Water Conservation" pp. 25, (Tashkent, 2005);

3. Resolution of the President of the Republic of Uzbekistan dated November 27, 2017 NP-3405 "On the State Program for the Development of Irrigation and Improvement of Irrigated Lands for 2018-2019"

4. D.R. Bazarov, S.K. Khidirov, U.A. Kakhkharov, D. Drapun, Problems of operation of the protective structures of Amudarya River. "Safety of energy facilities" periodic scientific, technical and industrial collection, M., Issue No. 2 (20), pp. 37-42, (2015);

5. O.Y. Glovatsky, R.R. Ergashev, N.R. Nasirova Improving the operational reliability of pumping stations with diagnostic methods // Journal "Hydraulic Engineering" No. 12, (Moscow, 2017);

6. O.Y. Glovatsky, E.A. Pecheykina, Sh.R. Rustamov, Assessment of the reliability of hydraulic systems of irrigation pumping stations // International Scientific and Practical Conference "Environmental Aspects of Land Reclamation, Hydraulic Engineering and Water Management of the Agro-Industrial Complex" (Kostyakovskie readings). AllRussian Scientific Research Institute of Hydrotechnics and Land Reclamation. (Moscow, 20170;

7. O.Y. Glovatsky, R.R. Ergashev, S.R. Rustamov, Operation and research of large pumping stations. // Lap Lambert Academic Publishing, pp. 170, (2013); 
8. T.S. Kamalov, K. Muminov, Z.E. Yusupov, The transfer function of the system "pumppipeline" // J. "Problems of informatics and energy" No. 2 pp. 47-50, (2004);

9. T.S. Kamalov, S.S. Kholikov, U.A. Tojiev, the question of the risk and safety of pumping stations and cascades of a water-driven station. // Problems of computer science and energy, No. 6. pp. 36-42 (2006);

10. M. Mamajonov, Analysis of operating conditions of pumping stations for agricultural purposes. // Bulletin of agrarian science of Uzbekistan. Tashkent state University No. 1, pp.77-80 (Tashkent, 2004);

11. M. Mamajonov, B. Uralov, H. Tursunov, The reasons for the reduction in water supply to pumping units of irrigation systems. // Agriculture of Uzbekistan, No. 1, pp. 27-29 (2005);

12. M.M. Muhammadiev, B.U. Urishev and others. Energy-efficient technologies in the operation of pumping stations. Monograph. T: Tashkent State Technical University, pp. 102, (2012);

13. M.M. Mukhammadiev, B.U. Urishev, F.Z. Nosirov, Improving the Efficiency of Water Intake Systems of Pumping Stations. Journal Hydrotechnical Construction, No. 1, pp. 34-36 (2010);

14. F. Mütsel, Operational reliability and efficiency of pumping stations // Water supply and sanitary engineering. No. 1. pp. 43, (2006);

15. A.Y. Naimanov, Reliability of water supply and wastewater systems // Water supply and sanitary engineering. №7, pp. 30-35. (2006);

16. O.Y. Glovatsky, N.R. Nasirova, R.R. Ergashev, Safety assessments and improving the reliability of the hydraulic unit of large pumping stations // Scientific and practical journal "Ways to improve the efficiency of irrigated agriculture" Novocherkassk, No. 2 (62), (2016);

17. M.M. Mukhammadiev, B.U. Urishev, F.Z. Nosirov, Deposition of sediment particles in the pump station's anchorage chamber. - The magazine "Hydraulic Engineering", No. 10, pp. 22-24 (2016);

18. S.Y. Petrenko, Parameters of reliability operation of pumping stations and measures for their improvement // Engineering reporter of Don. No. 4. pp. 110-114, (2006);

19. V.A. Khalmatov, Kh.K. Toshmatov, Reliability of pumping stations // Reporter of Tashkent State Technical University, T. No. 4, 34-38, (1996);

20.D.S. Khasanov Studies of reliability of the centrifugal pump // TIIAME, pp. 245, (1987);

21. O.Y. Glovatsky, R.R. Ergashev, Sh.R. Rustamov / Monography Lap Lambert Academic Publishing. pp. 170, (Saarbruken 2013). 